Artigo recebido em 16/02/2015 Aprovado em 19/04/2015

David Renault Universidade de Brasília (UnB) renault.david@gmail.com

Jornalista, doutor em

História (UnB, 2006), mestre em Comunicação (UnB, 1997). Professor da Faculdade de Comunicação (UnB). Linha de Pesquisa: Jornalismo e Sociedade. Área de Pesquisa: Jornalismo e História, Representação social.

Produção recente: A Era FHC nas representações da mídia impressa.

Elizabeth Cataldo Universidade de Brasília (UnB) -

ecataldo@uol.com.br

Jornalista, mestre em Comunicação Social (UnB, 2015), pós-graduada em Comunicação Internacional (City University, Londres,

1999). Atuou como jornalista em alguns dos principais veículos de comunicação do país.

Coorganizadora do livro Brasília aos 50 anos. Que cidade é essa?, publicado em 2010.

Estudos em Jornalismo e Mídia Vol. $12 \mathrm{~N}^{\circ} 1$ Janeiro a Junho de 2015, ISSN: 1984-6924

\section{Múltiplas temporalidades nas plataformas em tempo real}

\author{
David Renault e Elizabeth Cataldo
}

\section{Resumo}

A discussão sobre a temporalidade nos produtos de mídia em fluxo contínuo é o ponto central do artigo, que busca referências na moldura teórica dos estudos de Newsmaking e gêneros jornalísticos. A pesquisa realizada sobre os serviços informativos Broadcast e Valor PRO, voltados para os mercados financeiros e corporativo, buscou identificar os espaços de interpretação e opinião, que convivem com os conteúdos de natureza informativa e factual. Os valores culturais e os papéis dos jornalistas estão em questão nesses ambientes de máxima aceleração nas rotinas produtivas. Os indicadores apurados tiveram como objetivo também a aferição do grau de precisão das informações prestadas nas coberturas simultâneas aos acontecimentos. $\mathrm{O}$ próprio conceito de "tempo real" comporta diferentes definições, que estão inseridas nos estudos revisados para se abordar as múltiplas temporalidades encontradas nas plataformas pesquisadas.

\section{Palavras-chave}

Jornalismo, Tempo real, Newsmaking, Gêneros jornalísticos, Mudanças estruturais.

\begin{abstract}
The discussion on temporality in media products in a continuous flow is the central point of the article, which seeks references in the theoretical framework of Newsmaking and journalistic genres studies. The research on information services Broadcast and Value PRO, both focused on financial and corporate markets, sought to identify the areas of interpretation and opinion that live with the informative and factual content. Cultural values and roles of journalists are involved in this environment of maximum acceleration of routine production. The found indicators were aimed also the measurement of the degree of accuracy of the information provided in the simultaneous coverage of the events. The very concept of "real-time" gathers different definitions, which are inserted in the studies reviewed in order to address the multiple time frames found in the surveyed platforms.
\end{abstract}

\section{Keywords}

Journalism, Structural Changes, Real time, Newsmaking, Journalistic genres. 


\section{percepção de que a re- lação do jornalismo com a temporalidade é um dos eixos estrutu- rantes dessa prática so-} cial permeia as reflexões sobre as marcas da aceleração produtiva na mídia contemporânea. A noção de "tempo real", que se generalizou de forma imprecisa e comporta definições destoantes, está inserida no ambiente comunicacional em que as informações se sucedem de forma fragmentada e efêmera. Na busca do espaço que lhes garanta a produção de sentidos que caracteriza o percurso histórico da profissão, os jornalistas são instados a redefinir papéis e valores culturais, em meio a um processo de mudanças estruturais na mídia.

Franciscato (2005, p. 15) enfatiza que o jornalismo opera uma temporalidade específica ao sofrer o impacto das transformações sociais, políticas e econômicas, e realimentar o ciclo temporal. "O jornalismo é uma prática social voltada para a produção de relatos sobre eventos do tempo presente", afirma. O autor dedica-se a aprofundar o conceito de atualidade, desdobrando-o em cinco categorias descritivas dos fenômenos temporais impregnados na atividade jornalística: instantaneidade, simultaneidade, periodicidade, novidade e revelação pública. Nesse contexto, a dimensão de tempo real está identificada com a noção de simultaneidade e instantaneidade, assumindo importância crescente na esfera da produção noticiosa.

A distinção pertinente apresentada por Franciscato (2005), que adotamos neste artigo, identifica a instantaneidade com as transmissões diretas de áudio e vídeo, enquanto a noção de simultaneidade é mais congruente com a reprodução de informações em fluxo contínuo no formato textu- al. As duas instâncias temporais podem ser abrigadas no conceito de tempo real, cada uma delas referenciada em uma característica distintiva. Franciscato (2005, p. 235-236) ainda sublinha que a expressão tempo real constituiu-se como um sentido de senso comum "para designar um agregado de práticas e saberes que giram em torno do uso da tecnologia com vistas à instantaneidade e à simultaneidade em áreas diversificadas".

Em um dos trabalhos pioneiros sobre o tema, Elizabeth Brandão (1999) adotou a noção de que tempo real significa "informação sendo transmitida enquanto está acontecendo o fato, transmissão simultânea ao acontecimento". Adghirni e Moraes (2010) elegem o conceito de fluxo contínuo para classificar a nova forma de temporalidade proporcionada pela internet, que é a informação permanente. $\mathrm{Na}$ concepção das autoras, "é preciso um certo tempo para elaborar, digitar e disparar o mecanismo tecnológico que vai distribuir a informação, mesmo que sejam segundos depois do fato ocorrido" (2010, p. 237).

A abordagem de Adghirni e Moraes (2010) passa também pela possibilidade de que, no universo da internet, ocorra um processo de fabricação artificial da novidade, ao se reavivar nas home pages e páginas internas dos sites informações que foram fornecidas anteriormente. "Um mesmo produto informativo é reiterado em diferentes ritmos aproximados, dando a impressão de renovação de conteúdos nem sempre verdadeira", alertam (2010, p. 240). Os argumentos utilizados pelas autoras justificam a preferência pela denominação de informação em fluxo contínuo.

O foco na manifestação jornalística baseada na escrita, que nos propomos anali- 
sar na dimensão temporal, ainda comporta outras definições de tempo real. Jorge (2013) menciona que a referência ao real time tornou-se sinônimo de notícias frescas, apuradas pouco antes de sua publicação nos sites da internet. A transmissão de acontecimentos e eventos em rádio e televisão caracterizaria a notícia em tempo real, enquanto a internet, ao divulgar informações sobre o desenrolar das coberturas, corresponderia ao "near time, ou tempo próximo" (JORGE, 2013, p. 28-29).

Os estudos mencionados abriram caminho para a realização de pesquisa quan-

\section{Dissecar a cultura do jornalismo faz} parte do esforço de conhecer mais sobre a produção de notícias

titativa e qualitativa sobre dois produtos de informação voltados para os mercados financeiro e corporativo - Broadcast e Valor PRO -, que têm nas coberturas em tempo real sua característica mais marcante. A pesquisa foi realizada no âmbito do Programa de Pós-Graduação em Comunicação Social da Universidade de Brasília (UnB), como parte dos requisitos necessários à obtenção do título de Mestre em Comunicação Social pela linha de pesquisa Jornalismo e Sociedade ${ }^{1}$.

À luz dos conceitos revistos, validamos as seguintes definições para o nosso objeto de estudo:

- Cobertura jornalística em tempo real, como sinônimo de produção e transmissão de informação simultânea aos acontecimentos, da maneira mais próxima possível ao tempo do registro dos fatos;

- Informação em fluxo contínuo, como sinônimo de edição de conteúdos jornalísticos em sequência contínua, abrangendo tanto coberturas em tempo real como textos jornalísticos em tempo diferido, sem relação de simultaneidade com os acontecimentos;

- Jornalismo ao vivo, seguindo a classificação proposta por Franciscato (2005), representa um conceito restrito às transmissões eletrônicas instantâneas, de áudio e vídeo.

\section{Newsmaking e gêneros jornalísticos}

$\mathrm{O}$ enquadramento teórico da pesquisa sobre os produtos de informação em fluxo contínuo, com coberturas em tempo real, foi baseado nos estudos e conceitos do Newsmaking e de gêneros jornalísticos. Com foco no emissor, a pesquisa abordou as experiências da Agência Estado (AE), responsável pelo Broadcast, e do Valor Econômico, a que se vincula o Valor PRO. O objetivo principal foi o de detectar os espaços de interpretação e opinião que convivem com os conteúdos informativos nessas plataformas em tempo real. Inseridos no ambiente dos mercados financeiro e corporativo, esses produtos de mídia desafiam as redações jornalísticas a conciliar a produção de notícias em ritmo de milésimos de segundos com a capacidade de refletir e opinar sobre os acontecimentos reportados.

Vizeu (2010, p. 223) assinala que nos estudos sobre emissores é possível encontrar "as articulações, conexões e relações existentes entre a cultura profissional dos jornalistas, a organização do trabalho e
${ }^{1} A$ dissertação de Mestrado intitula-se Os novos desafios do tempo real-Múltiplas temporalidades nas plataformas do Broadcast e Valor PRO. De autoria de Elizabeth Cataldo, sob a orientação do prof. Dr. David Renault, a dissertação foi defendida em fevereiro de 2015. 
dos processos produtivos". Woolf (2010) defende que se penetre na intimidade da dinâmica de elaboração da notícia para que seja possível "conhecer não apenas os sistemas de valores, de representações, de imaginário coletivo que eles propõem, mas também o modo, os processos, as restrições e as limitações com que se realizam" (2010, p. 189). Ambos convergem para a abordagem consagrada pela socióloga norte-americana Gaye Tuchman de que as notícias traduzem uma realidade socialmente construída e não um espelho da realidade.

Compreender a atividade jornalística significa entender como agem os mecanismos acionados pelos profissionais da comunicação para digerir os acontecimentos factuais e devolver ao público a representação da realidade. Nesse sentido, dissecar a cultura profissional dos jornalistas faz parte do esforço de aprofundar o conhecimento sobre esses mecanismos processuais acionados para a produção de notícias. Traquina (2004, p. 117) é um dos autores que conferem importância central aos marcos culturais dos jornalistas, que "professam saber o que é notícia e como escrevê-la".

$\mathrm{O}$ autor português aborda o processo de afirmação profissional dos jornalistas, que se acentua a partir do final do século XIX, com a reivindicação de um monopólio de saberes específicos, assumindo como certo "o direito e a obrigação de mediar e simplificar, cristalizar e identificar os elementos políticos no acontecimento noticioso" (TRAQUINA, 2004, p. 89). É também na dimensão cultural que os estudiosos do Newsmaking situam a relação dos jornalistas com a temporalidade.

Souza (2002) refere-se à definição de Schelesinger (1977) de que a profissão de jornalista demandaria um excepcional grau de precisão nos timings. Os jornalistas teriam uma "espécie de cronomentalidade" (2002, p. 47) que os levaria a associar a classificação de notícias ao fator tempo e a situar a capacidade de vencê-lo como demonstração inequívoca de competência profissional. Na visão de Traquina $(2008$, p. 50), "os jornalistas têm uma maneira própria de sentir o tempo, obsessiva e frenética". A marca da precariedade na produção noticiosa está presente historicamente na atividade jornalística justamente pela pressão do tempo, acentuada pela acirrada competição na mídia, que levaria os profissionais a relatar as histórias "em situação de incerteza" (SOUZA, 2002, p. 48).

As características de premência do tempo e urgência, acentuadas pela concorrência entre os diferentes produtos de mídia, nos interessam de perto na abordagem proposta sobre os serviços informativos em fluxo contínuo Broadcast e Valor PRO. Até que ponto essa situação de incerteza a que se refere Souza (2002), no contexto dos produtos tradicionais impressos, se torna ainda mais aguda nas coberturas factuais em tempo real é uma das indagações que animaram o projeto de pesquisa. Assim como buscamos o contraponto da interpretação e da opinião como elementos integrantes de um universo informacional ditado pela extrema aceleração nas rotinas produtivas das redações.

Schlesinger (1978) analisa que o caráter efêmero e a dinâmica da produção jornalística contribuem para o estreitamento de contexto e a redução da "significatividade" da notícia:

(...) a produção é organizada de modo tal que sua dinâmica fun- 
damental enfatiza a efemeridade das histórias. Se uma notícia se prolongar de um dia para outro, assume-se que o público, depois de um dia de exposição, esteja adequadamente familiarizado com o problema, de maneira que permita que o background seja amplamente dado por conhecido. São sempre os desenvolvimentos do dia presente que ocupam o primeiro plano. O corolário desse ponto é que existe uma tendência inerente às notícias de serem emolduradas de modo descontínuo e anistórico, e isso implica um estreitamento do contexto e, portanto, uma redução de significatividade (SCHLESINGER, 1978, p. 105, apud WOLF, 2002, p.232, grifo nosso).

Ao situar a urgência como valor dominante, a atividade jornalística molda um conceito de atualidade que afeta o news judgment, aponta Souza (2002), o que se conecta, ainda no âmbito do Newsmaking, ao processo de seleção e filtragem das notícias. Os estudos de Schoemaker e Vos (2011) sobre a atuação dos gatekeepers indicou um caminho válido para a investigação que conduzimos, especialmente pela referência de que o processo de $g a$ tekeeping comporta diferentes etapas e pode começar com o repórter, na rua, e não apenas dentro das redações. A dinâmica de produtos como o Broadcast e Valor $P R O$, pela extrema aceleração das coberturas factuais, delega aos repórteres boa parte do esforço de seleção e filtragem das informações mais importantes para o seu público.

Além disso, os autores norte-americanos problematizam a relação entre jornalistas e fontes, escapando de uma visão estreita que apresenta o profissional do jornalismo como um receptáculo passivo das informações e interesses das fontes com as quais se relaciona. "Eles [os jornalistas] interpretam as mensagens, resolvem ambiguidades, fazem suposições sofisticadas sobre coisas que não observaram diretamente e inferências sobre possíveis relações", afirmam Schoemaker e Vos (2011, p. 57), numa perspectiva que também adotamos neste artigo. Isso não significa que ambos desconheçam a importância dos níveis organizacionais e das práticas rotineiras no processo de gatekeeping, mas sim que valorizam também o papel dos indivíduos na execução dos procedimentos de seleção.

São considerações relevantes para 0 ambiente jornalístico que pesquisamos, caracterizado pela especialização na área econômico-financeira. É nesse campo especializado que se encontrariam as relações de dependência mais profundas estabelecidas entre jornalistas e fontes, classificadas como "simbióticas" por Woolf (2010, p. 239). Souza (2002, p. 70) aponta o risco de que os jornalistas especializados cultivem "laços mais profundos com as fontes, no seio de uma relação negocial onde se vão estabelecendo direitos e obrigações recíprocas", o que poderia, em determinados momentos, comprometer ou condicionar o jornalista a desvirtuar a informação.

Torna-se relevante retornar aos conceitos que Schoemaker e Vos (2011) aplicam ao universo jornalístico em que a demanda por precisão é muito elevada, como acontece nos produtos em fluxo contínuo para os mercados financeiros e corporativos informações equivocadas podem levar a 
perda de valores na escala de bilhões de reais ou dólares. Os autores destacam o modelo do second guessing (segunda leitura), nos termos propostos por Hews e Graham (1989), que analisam o comportamento dos gatekeepers em busca de precisão e confiabilidade das informações selecionadas para o público. Nesse modelo, que reitera o papel ativo dos jornalistas, os profissionais tentam corrigir eventuais equívocos de informação e reinterpretar as mensagens filtradas à luz de seu conhecimento prévio sobre os temas abordados.

No âmbito dos estudos de gênero, identificamos elementos para desvendar as características formais e funcionais dos conteúdos jornalísticos inseridos nas plataformas em tempo real do Broadcast e do Valor PRO, em busca das manifestações de caráter interpretativo e opinativo que abrigam. Esse marco teórico não implica desconhecer, no entanto, a dimensão histórica e social dos gêneros jornalísticos.

\section{As notícias traduzem uma realidade socialmente construída}

A própria noção de produtos associados às Tecnologias de Informação e Comunicação (TICs), como é o caso, já significa indicar um tempo histórico determinado e realidades sociais específicas. "Compreender gênero é compreender a prática jornalística" - assinala Lia Seixas (2009, p.5), o que em alguma medida enlaça os campos teóricos do Newsmaking e dos gêneros, em foco neste artigo.

A classificação proposta por José Marques de Melo (1994), ainda hoje uma re- ferência fundamental nos estudos de gêneros jornalísticos no Brasil, foi adotada por nós como parâmetro para a realização da pesquisa. Nos anos 1980, o autor não identificou a categoria interpretativa no jornalismo brasileiro, considerando adequado inserir os conteúdos de cunho analítico na categoria informativa. Mais à frente, de acordo com entrevista concedida à pesquisadora Lia Seixas, em 2009, passou a considerar cinco categorias autônomas: informativa, opinativa, interpretativa, diversional e utilitária.

Como enfatiza Seixas, o entendimento de Melo sobre a categoria interpretativa coincide com o sentido original em inglês da palavra interpretação, que remete a explicação e educação. Na pesquisa que realizamos, as categorias que nos interessaram mais de perto foram a informativa, a opinativa e a interpretativa, predominantes nos produtos de mídia abordados. Cabe destacar, como fazem os estudiosos do tema, que as fronteiras entre as diferentes categorias que abrangem os gêneros jornalísticos são fluidas e podem ser atravessadas de forma frequente por uma mescla de características, o que dificulta o seu enquadramento para efeito de quantificação. No espaço digital, onde situamos os produtos pesquisados, essas fronteiras podem ser ainda mais tênues, com a emergência de novos gêneros e formatos. De qualquer maneira, a distinção das diferentes categorias é útil como referência para avaliar os contornos do jornalismo praticado nas diversas plataformas.

Melo (1994) tem observações relevantes também quanto ao perfil do jornalista que exercita a opinião e a interpretação, como no gênero comentário. "O comentarista é geralmente um jornalista com grande experiência e tirocínio, que acompanha os 
fatos não apenas na sua aparência, mas possui dados nem sempre disponíveis ao cidadão comum" (1994, p. 105). O autor destaca ainda as qualidades de especialista que são necessárias para a prática da análise e da opinião, um aspecto significativo para a nossa abordagem na pesquisa.

"Comentar é uma tarefa que pressupõe ancoragem informativa e perspectiva histórica. (...) quem recorre ao comentário quer dispor de uma bússola para entender a contemporaneidade" (MELO, 1994, p. 106). Souza também compartilha a mesma visão: “(...) só jornalistas especializados, com um vasto domínio dos assuntos e uma ampla rede de contatos, podem, judiciosamente, enveredar pela análise e pela interpretação dos fenômenos" (2002, p. 71). O desempenho dos jornalistas nessa área nobre do exercício profissional depende, portanto, de uma formação sólida, experiência e conhecimento do tema.

Ainda no contexto da pesquisa, são centrais as considerações de Traquina (2004) (2013) a respeito da importância do formato da pirâmide invertida na construção da identidade do jornalista. A utilização desse formato, a partir de 1900 , confere aos repórteres habilidade profissional específica, que vai ajudar a legitimar o seu papel na sociedade. A pirâmide invertida e o lide rompem com o relato cronológico e permitem que os jornalistas exercitem a interpretação sobre o significado dos acontecimentos. Jorge (2013, p. 101) reforça que o modelo da pirâmide "trouxe, pari passu com a padronização da escrita jornalística, os conceitos de objetividade, concisão e brevidade, precisão e exatidão, imparcialidade e neutralidade".

\section{Pesquisa quantitativa e qualitativa}

A etapa quantitativa da pesquisa foi realizada nos dias $23,26,27,28$ e 29 de maio de 2014, concentrando-se no principal informativo jornalístico da plataforma do Broadcast, o AE-News, e no noticiário unificado do Valor PRO. A metodologia utilizada foi a análise de conteúdo, com base nos conceitos e procedimentos preconizados por Laurence Bardin (2011). O objetivo não foi o de comparar os dois produtos voltados para os mercados financeiro e corporativo, mas sim utilizá-los como referências válidas da produção jornalística em fluxo contínuo, com coberturas em tempo real de máxima aceleração - em função das plataformas tecnológicas avançadas que utilizam e das necessidades do público a que se dirigem.

Os serviços informativos, que são restritos aos assinantes e demandam aplicativos específicos das empresas responsáveis para serem acessados, foram acompanhados no período de 6 horas da manhã às 20 horas. O quadro categorial baseou-se nas classificações informativa, opinativa e interpretativa, suficientes para enquadrar os diferentes gêneros abrigados nas plataformas pesquisadas. Na organização do corpus da pesquisa, adotamos o critério de unidade de informação (UI) para cada conteúdo identificado nas três categorias e tabulamos os resultados para gerar indicadores válidos para inferência e interpretação. As plataformas pesquisadas comportam uma ampla composição de dados e informações, como cotações de bolsas, moedas e títulos, assim como gráficos e tabelas. Porém, apenas os conteúdos jornalísticos no formato textual escrito foram objeto da pesquisa.

Foram enquadrados na categoria informativa os seguintes gêneros: "pisca" ou highlight (títulos sem um texto imediato e correspondente, como recurso para ace- 
lerar a publicação de informações), nota, notícia, agenda e entrevista. Na categoria interpretativa, situaram-se os formatos de cenário, análise, bastidores e reportagens especiais. Na categoria opinativa, foram classificados os blogs, colunas, comentários e artigos de especialistas convidados. Como critério fundamental, consideramos todos os formatos e gêneros inseridos no campo jornalístico, mesmo aqueles que apenas introduziam íntegras de comunicados institucionais e de serviços. A perspectiva é a de que todos os conteúdos passaram pelo processo de gatekeeping, o que configura o crivo jornalístico antes de sua publicação.

No Broadcast, foi analisado um total de 2.836 unidades de informação durante os cinco dias pesquisados, que excluíram o final de semana pela baixa representativa no contexto dos produtos voltados para os mercados financeiro e corporativo. Do total de UI, $92,42 \%$ estavam enquadradas na categoria informativa. Se computados apenas os piscas, chegamos a uma proporção de $50,32 \%$ do total de unidades de informação classificadas. Isso significa que praticamente metade das informações contidas no Broadcast, que tomamos como sinônimo do $A E-N e w s$ na pesquisa, resultaram de coberturas em tempo real, que lançam mão do recurso dos piscas para agilizar a publicação de informações na plataforma. Consideramos que o formato dos piscas reflete, por excelência, a dinâmica da informação em tempo real, embora possa ser utilizado de forma residual também para destacar coberturas em tempo diferido.

Ainda no Broadcast, as unidades de informação enquadradas nas categorias interpretativa e opinativa somaram 215 , o equivalente a $7,58 \%$ do total. Esse re- sultado significou uma média diária de 43 textos dessas categorias, que diferem dos textos e caráter informativo e factual. Isoladamente, a categoria interpretativa apresentou 192 UI, restando outras 23 unidades para a categoria opinativa. $\mathrm{Na}$ tabulação dos dados da pesquisa, exercitamos também o cálculo da proporção de cada categoria com a subtração dos piscas. Como as informações contidas nos piscas são replicadas posteriormente em textos completos, consideramos que há uma superposição de conteúdos na categoria informativa. Assim, ao subtrair esses $h i$ ghlights, que têm a função de antecipar informações complementadas logo adiante, encontramos uma proporção de 15,23\% das categorias interpretativa e opinativa em relação ao total de UI.

No Valor PRO, os mesmos critérios foram aplicados. O total de unidades de informação classificadas nos cinco dias da pesquisa chegou a 2.004, das quais a categoria informativa respondeu por uma parcela de $90,77 \%$. Significa que a soma das categorias interpretativa e opinativa representou $9,23 \%$ do total, o equivalente a 185 UI. Na média diária, essas duas categorias responderam por 37 textos. Ressalte-se que os gêneros da categoria interpretativa, com 152 UI, são predominantes em relação à categoria opinativa, que somou 33 UI. O mesmo exercício realizado nos conteúdos do Broadcast, ou seja, a exclusão dos piscas resultou numa proporção das categorias interpretativa e opinativa de $13,47 \%$ do total, cabendo a parcela majoritária de $86,5 \%$ aos conteúdos de caráter informativo.

Apuramos também na pesquisa a incidência dos conteúdos diferenciados, de cunho interpretativo e opinativo, ao longo das 14 horas em que acompanhamos os 
noticiários dos dois produtos. Foi possível constatar uma distribuição constante e regular desses conteúdos que diferem das coberturas informativas, no decorrer do período de apuração. Com isso, consideramos pertinente afirmar que as interpretações e opiniões pontuam os noticiosos das plataformas do Broadcast e do Valor $P R O$, como contraponto e complemento às informações fragmentadas e efêmeras produzidas nas coberturas em tempo real. Avaliamos que existe uma inserção orgânica do jornalismo interpretativo e opinativo nessas plataformas.

Com o objetivo de aferir o nível de precisão das informações prestadas nesses produtos, somamos todas as UI apuradas nas duas plataformas e calculamos os avisos de correção de erros de edição e informação. No total de 4.840 unidades de informação encontradas nos cinco dias pesquisados nos dois produtos, o percentual de erros corrigidos chegou a $0,68 \%$, o equivalente a 33 correções - dados que consideramos eloquentes sobre o grau de precisão. As características dos produtos de informação em fluxo contínuo para os mercados financeiro e corporativo podem nos assegurar uma margem de confiabilidade nesses dados, na medida em que a correção imediata de erros relevantes é uma demanda do próprio público profissional que paga por esses serviços especializados. Ressalvamos que não nos detivemos na dimensão e repercussão dos erros cometidos.

Na etapa qualitativa da pesquisa, buscamos avaliar e contextualizar os resultados obtidos na fase quantitativa. Para isso, foram realizadas seis entrevistas em profundidade e semiestruturadas com profissionais das redações da Agência Estado, responsável pelo Broadcast, e do Valor
Econômico, que produz o Valor PRO. Realizamos três entrevistas com jornalistas de cada redação, incluindo os profissionais que ocupam os principais cargos no comando editorial de cada uma delas: o editor-chefe da $A E$, João Caminoto, e a diretora de redação do Valor, Vera Brandimarte. As entrevistas foram realizadas por telefone, com exceção da repórter especial e colunista do Broadcast Adriana Fernandes, que foi entrevistada pessoalmente em Brasília. Os demais profissionais estão baseados em São Paulo.

Os depoimentos colhidos atestaram que a produção de conteúdos interpretativos e opinativos não é episódica ou eventual nos produtos pesquisados e sim parte da estratégia editorial e empresarial das empresas que os controlam - o Grupo Estado, no caso do Broadcast, e o Valor, que é resultado da associação do Grupo Globo com o Grupo Folha e produz o Valor PRO. A dinâmica de informar com rapidez os fatos, no formato ultrafragmentado dos piscas, é desdobrada em etapas posteriores da produção jornalística, em que as redações se voltam para a análise e contextualização dos eventos considerados mais relevantes para os seus assinantes.

Há uma predominância dos jornalistas seniores na produção dos conteúdos interpretativos e analíticos, justamente pelo maior repertório e conhecimento desses profissionais para analisar os acontecimentos. Ao contrário das expectativas iniciais, anteriores à realização da pesquisa, não se constatou uma tendência crescente de utilização de profissionais não jornalistas nas redações, mesmo com a flexibilidade proporcionada pela extinção da exigência obrigatória do diploma para o exercício da profissão. O olhar do jornalista e suas habilidades específicas foram valorizados de 
maneira enfática nas entrevistas com a direção editorial do Valor. Por sua vez, destacou-se no depoimento do editor-chefe da $A E$ a política de oportunidades abertas a todos os profissionais na ocupação dos espaços analíticos e opinativos.

O impacto da aceleração das rotinas produtivas é de grande magnitude nas duas redações. Ambas atuam como redações integradas, que servem a diferentes plataformas, mas o Valor tem essa característica mais acentuada, pelo modelo de comando único nas editorias que produzem o jornal impresso Valor Econômico e o serviço Valor PRO. Nas dobras do processo de integração das redações, foi possível detectar sinais de precariedade em seu funcionamento pelos ciclos de corte de custos na área de recursos humanos, o que acarreta tensões adicionais a um processo de produção já bastante retesado pelas exigências, a um só tempo, de celeridade e precisão nas informações.

As redações dos dois produtos também compartilham a preocupação constante com o aprimoramento da formação dos jornalistas que empregam. O grau de especialização na área econômico-financeira dos produtos pesquisados mobiliza os dirigentes da área editorial a oferecer cursos de formação em áreas críticas do noticiário sobre mercados de juros, ações e câmbio, assim como de setores e empresas de interesse do público profissional. A qualificação foi a resposta mais constante para os questionamentos a respeito das estratégias editoriais destinadas a conciliar a velocidade nas rotinas produtivas com a menor margem de erros possível.

Os detalhes operacionais extraídos nas entrevistas em profundidade mostraram que o processo de gatekeeping está presente nos produtos pesquisados, com a característica de participação ativa dos repórteres nessa dinâmica, ressaltada nos estudos revistos sobre o tema. Confirmam-se também as premissas dos conceitos teóricos de que o perfil de relacionamento entre fontes e jornalistas no contexto de produtos especializados é intenso e próximo. Ao mesmo tempo, reiteramos a percepção de que os gatekeepers têm um papel ativo no esforço de checagem das informações para garantir a confiabilidade das informações prestadas.

A dimensão cultural nos ambientes das redações dos dois produtos transparece nos depoimentos sobre a carga de resistência, e até mesmo de preconceito, em relação ao ritmo jornalístico em fluxo contínuo. A imposição da linha cronológica nas coberturas simultâneas aos acontecimentos, por força da velocidade em que as informações são transmitidas, contraria valores fundantes do jornalismo. A subversão da pirâmide invertida confronta um dos símbolos da interveniência do profissional na estrutura narrativa dos acontecimentos para a produção de sentidos. As dificuldades de apropriação dos "furos" pelos jornalistas, nas plataformas digitais, é outro ponto sensível da cultura profissional colocada em xeque.

\section{Conclusões}

Os resultados da pesquisa quantitativa e os depoimentos na etapa qualitativa demonstram que a produção de conteúdos interpretativos e opinativos está presente nas plataformas em tempo real, que mostram a predominância das informações de caráter factual e da estrutura narrativa ultrafragmentada. A frequência com que os textos enquadrados nas categorias interpretativa e opinativa são editados indicam que cumprem a função de complementar 
a contextualizar os conteúdos de caráter informativo, tornando-os indissolúveis no contexto dos produtos Broadcast e Valor PRO. Nesse sentido, é possível concluir que, também nos ambientes midiáticos especializados voltados para públicos profissionais, há espaço e demanda por análise e opinião.

As coberturas em tempo real, em que se destaca o recurso à edição de títulos em sequência, sem textos correspondentes e imediatos, quebram o perfil da pirâmide invertida e do lide ao adotar uma linha cronológica no acompanhamento simultâneo dos eventos. Mesmo que não se considere o noticiário factual um espelho da realidade, e sim comprometido também com uma carga de interpretação e enquadramento, a cobertura ultrafragmentada e acelerada implica uma redução de significatividade pela própria exiguidade do tempo em que se produz. Os textos de interpretação e opinião asseguram o resgate do formato histórico do jornalismo para dotar de sentido os acontecimentos, reforçando também o protagonismo dos profissionais no papel de intérpretes da realidade.

A baixa incidência de erros de informação e edição nos produtos pesquisados, em números muito expressivos, contesta a noção generalizada de que a velocidade acentuada na produção noticiosa aumentaria de forma exacerbada os equívocos cometidos pelos profissionais. As duas redações são submetidas à pressão constante pela precisão e a qualificação dos recursos humanos empregados é considerada a peça-chave nesse processo. O aprimoramento da formação dos jornalistas, com o grau de especialização necessário, não é resposta apenas para a maior exatidão dos conteúdos informativos, mas também condição crucial para o exercício da interpretação e da opinião.

A pesquisa permitiu, por fim, consolidar a perspectiva adotada a partir dos estudos de Franciscato (2005) de que os produtos em fluxo contínuo extrapolam a dimensão da instantaneidade e da simultaneidade. São plataformas que operam múltiplas temporalidades e que buscam ampliar a capacidade de informar e contextualizar os eventos acompanhados. No enfrentamento do tempo que marca a atividade jornalística, os desafios que se colocam diante dos profissionais é o de ocupar as arenas digitais com toda a potencialidade de diferentes gêneros e formatos que o jornalismo oferece, atuando como protagonistas da reinvenção da mídia.

\section{Referências bibliográficas}

ADGHIRNI, Zélia Leal; MORAES, Francilaine de. Instantaneidade e memória na pesquisa sobre jornalismo online. In: LAGO, Cláudia;

BENETTI, Márcia (Orgs.). Metodologia de Pesquisa em Jornalismo. Petrópolis: Vozes, 2010.

BARDIN, Laurence. Análise de Conteúdo. São Paulo: Edições 70, 2011.

BRANDÃO, E. P. Da ciência ao mercado, a informação em tempo real. Tese (Dou- 
torado em Ciência da Informação). Universidade de Brasília. Brasília, 1999.

FRANCISCATO, Carlos Eduardo. A Fabricação do Presente. Aracaju: Editora UFS, 2005 .

JORGE, Thaïs de Mendonça. Mutação no Jornalismo: como a notícia chega à internet. Brasília: Editora Universidade de Brasília, 2013.

MELO, José Marques de. A Opinião no Jornalismo Brasileiro. 2. ed. rev. Petrópolis: Vozes, 1994.

SEIXAS, Lia. Redefinindo os Gêneros Jornalísticos. Covilhã (Portugal): LabCom Books, 2009.

SHOEMAKER, Pamela; VOS, Tim P. Teoria do Gatekeeping: Seleção e construção da notícia. Porto Alegre: Penso, 2011.

SOUZA, Jorge Pedro. Teorias da Notícia e do Jornalismo. Chapecó: Argos, 2002.

TRAQUINA, Nélson. Teorias do Jornalismo: Porque as notícias são como são. Florianópolis: Insular, 2004. v. 1.

VIZEU, Alfredo. O newsmaking e o trabalho de campo. In: LAGO, Cláudia; BENETTI, Márcia (Orgs.). Metodologia de Pesquisa em Jornalismo. Petrópolis: Vozes, 2010. p. 223- 236.

WOLF, Mauro. Teorias das Comunicações de Massa. São Paulo: Martins Fontes, 2010 .

Estudos em Jornalismo e Mídia está sob a licença Creative Commons 2.5 